\title{
Study on AC Contactor Performance UnderVoltage Sags
}

\author{
Surya Hardi ${ }^{1}$, Rohana ${ }^{2}$ \\ \{surya.hardi@usu.ac.id ${ }^{1}$,rohana@umsu.ac.id ${ }^{2}$ \} \\ ${ }^{1}$ Universitas Sumatera Utara, Dr. Mansyur Street, Medan,Indonesia \\ ${ }^{2}$ University of Muhammadyah Sumatera Utara, Medan, Indonesia
}

\begin{abstract}
AC contactor many found in industrial sectors. It function is to link induction motorto utility supply and recognicedsusceptible to voltage sags. The contactorconsist of primary and auxiliary contacts. The primary contact can opened if it is supplied by voltage sags. In an industry, a contactor is used to keep electric motors abruptly restart when the voltage sag return to normal. This studydiscussesbehaviour of three contactors caused byvoltage sags and interruption. The contactors are fabricated from distinct manufactures. Voltage sag characteristics used are sag magnitude, sag duration and also point on wave (POW) of sag initiation. The testing results show that the contactors performances are greatly influenced by them. The contactors are more susceptiblewhen theywere served with deeper and longer voltage sag. Susceptiblity of contactors to sag durationis rise when they were supplied by voltage sags with the POW near to $90^{\circ}$. The contactors susceptibities decrease when thesag occurs at three POWs which $\operatorname{are} 0^{\circ}$, $45^{\circ}$ and $90^{\circ}$.
\end{abstract}

Keywords: Contactors performance, sag magnitude, sag duration, point on wave of sag initiation

\section{Introduction}

Voltage sag caused by short circuit fault in power system. The large current resulted propagates to all network causeslarge voltage drop so the terminal voltage at receiving end to be decrease. According to IEEE Std. 1159 (1995) voltage sag is reduced voltage in magnitude from $90 \%$ to $10 \%$ of nominal voltage with sag duration from 0.5 cycles until one minute.If the magnitude of voltage sag islower than $10 \%$ is called as interruption.Sag duration is time difference between the start and end of voltage sag. Phase angle of the sinusoidal voltage which the voltage sag a start to happen is called POW of sag initiation. Sag magnitude and sag duration are primary characteristics of voltage sags. Those characteritics have great effect on susecptibility of equipments(Bollen, 2000)and (Dugan, R. C, et al. 2003).

Electrical contact of contactor will close when electromagnetic force larger than spring presure. The force is influenced by voltage supply magnitude that connected to magnetic coil so that produce current. When contactor to close contact needs larger current than current required to withstand them in normal condition. Electromagnetic force decreases when the contactor is supplied voltage sags. A contactor will drop out when magnitude of electrmagnetic force is lower than spring force. The spring leads to the contact retain in open positionsocurrent flows to induction motor intrrupted. Contactor many found in industrial sector that work to connect and disconect from supply voltage to prevent motor from suddenly restarting when the volatge back to normal.

In previous studies, research take into acount POW of sag initiation on contactor testing through experimental found in (Pohjanheimo, P. and M. Lehtonen, 2002) and (Iyoda, et al. 
2007). The studies take into consideration the POW in two values only which are $0^{\circ}$ and $90^{\circ}$. S.W et al. 2009 propose the POW $0^{\circ}$ until to $90^{\circ}$ in simulation model. The POW increases from $0^{\circ}$ to $90^{\circ}$ by step of $15^{\circ}$. The POWshave influence on contactor behaviour to drop out.

\section{Testing Of Contactor}

Three contactors with appelation $\mathrm{A}, \mathrm{B}$ and $\mathrm{C}$ are tested by an experiment at CERE laboratory in UniMAP. Those contactors have the same rating voltage and frequency but are manufactured from different plants. The experiment is displayed such asin Figure 1.

The contactor was supplied by an equipment SchaffnerProfline2100 Electromagnetic Compability. Many types power qualities can be producedby this equipment. One of them are voltage sag. Out put of voltage sag generator (VSG) can be adjusted to find voltage sag characteristic desired.

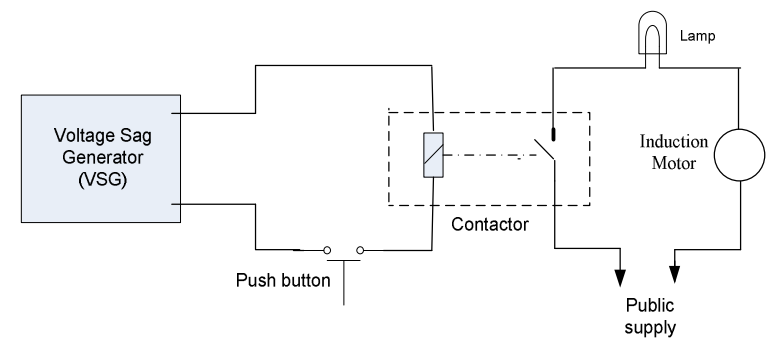

Fig. 1. Schematic circuitofexperiment

A $0.5 \mathrm{hp}$ induction motor was used as load. A $25 \mathrm{~W}$ incandescent lamp was used as indicator which it will off when the contactor drop out. The both devices wereconnected to public supply. The test procedure as follow;

(i) The experiment is beginning with out put of VSG is set to $70 \%$ of nominal voltage, $0^{\circ}$ the POW and sag duration of $10 \mathrm{~ms}$. The sag duration is increased by step of 10 until 200 milliseconds. Record the contactor did not drop out or drops out.

(ii) Sag magnitude reduced in step of $2.5 \%$ until $0 \%$ and then action in point (i) is replayed. The test is replayed 2 until 3 time to prevent error due to random diversity.

(iii) Repeat point (ii) for distinct the POW with increment of $15^{\circ}$ to $90^{\circ}$.

\section{Test Results}

\subsection{Contactor performance caused by voltagesag magnitude}

Implementation of contactor $\mathrm{C}$ when it was supplied by voltage sag in distinct characteristics is shown in Figure 2.. These figures are line voltage supplied and current waveformsthrough contactor.

Figure2 (a) illustrates contactor $\mathrm{C}$ when supplied by sag magnitude of $60 \%$ and sag duration of 100milliseconds. The contactor did not drop out and current waveform still oscilation in hoarizontal axe. Figure 2 (b)illustrates the contactor was supplied by lower sag which is $45 \%$ sag magnitude in same duration. The current still oscilation in a few cycles and then toward zero and it did not direct drop out.The performance contactor drop out is indicated by current waveform. From Figure 2, contactor is more susceptible when it supplied by lower sag magnitude. 


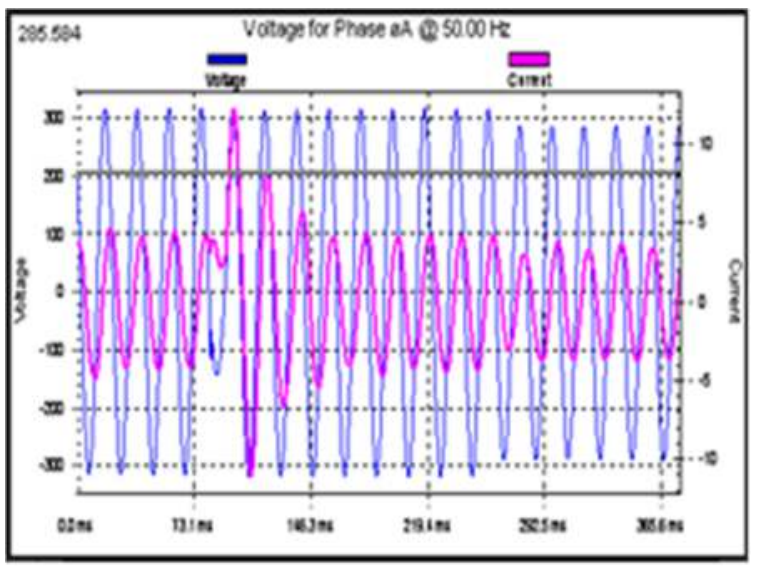

(a) $60 \%$ sag magnitude, 100milliseconds sag duration

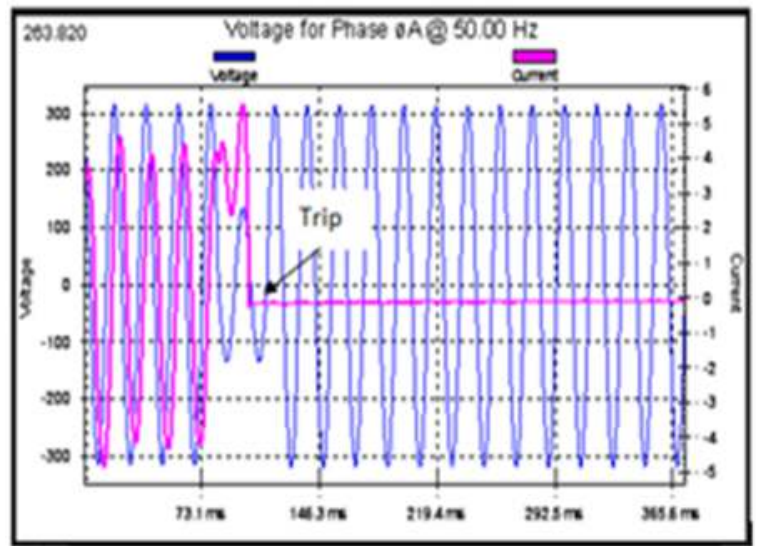

(b) $45 \%$ sag magnitude, 100 milliseconds sag duration

Fig. 2. Voltage and current waveforms for contactor C.

\subsection{Effect of magnitude and durationof voltage sag}

Figure 3 is one of three susceptible curves of the contactors. There are four different points for investigating namely $\mathrm{P}, \mathrm{Q}, \mathrm{R}$ and $\mathrm{S}$. Point $\mathrm{P}$ at (50\%; 40 milliseconds), Q at (40\%; 40 milliseconds), $\mathrm{R}$ at (20\%; 40milliseconds) and $\mathrm{S}$ at (20\%; 80milliseconds).

Positions of $\mathrm{P}$ and $\mathrm{Q}$ located in same sag duration (40milliseconds), but they have distinct sag magnitude which are $50 \%$ and $35 \%$, respectively. The point $\mathrm{P}$ indicates contactor response remains operated while at point Q the contactor dropped out. Posistion Q is deeper sag than P. Points R and S located at same magnitude of $20 \%$, but distinct in sag duration. Response of the contactor at those points is not similar. At point $\mathrm{R}$ the contactor did not drop 
out at $(20 \%$; 40milliseconds) whereas $\mathrm{S}$ indicates that the contactor is in dropping out condition at $(20 \% ; 80$ milliseconds).

Mostlyequipments are more susceptible if theyare subjected to deeper voltage sag and longer sag duration. This is also similar to study conducted by (George, et al. 2005) which they susceptibiliitiesincreased when they weresupplied to deeper voltage sag and longer sag duration.

\subsection{Effect of point on wave of voltage sag initiation}

Phase angle point of sinusoidal fundamental wave where voltage sag beginning occur is called POW of voltage sag initiation. In this study the POW take into account are $0^{\circ} ; 15^{\circ}$; $30^{\circ} ; 45^{\circ} ; 60^{\circ} ; 75^{\circ} ; 90^{\circ}$. Sucseptibilty curves resulted of testing in some POW are presented through Figure 4 until to Figure 6. The curves indicate susceptiblities values of contactors which they drop out. The contactor A has threshold voltage value is highest for POW of $30^{\circ}$ and $60^{\circ}$ such as in Figure 4.Highest value of the threshold voltage

is $40 \%$. Susceptibility of contactor against sag magnitude decreases for other POWs. Values of POWs of $0^{\circ}, 75^{\circ}$ and $90^{\circ}$ causes threshold magnitude voltage valuedecrease become to $30 \%, 30 \%$ and $20 \%$, respectively. Contactor is most susceptible to sag duration while it supplied by $75^{\circ}$ and $90^{\circ}$ the POWs. Value of sag duration is 20 milliseconds. In other word, 20 milliseconds is lowest value for sag duration.

Figure 5 indicates suceptibility of contactor B. Highest and lowest suceptibilities to voltage magnitude were achieaved when the contactor was supplied by the POW of $60^{\circ}$ and $90^{\circ}$, respectively. The threshold valuesare $47.5 \%$ and $30 \%$ of nominal voltage. For sag duration, highest susceptibity the contactor was obtained at 20 milliseconds when it was supplied by POWs of $75^{\circ}$ and $90^{\circ}$ but the threshold voltage are not similar.

Contactor $\mathrm{C}$ produce results for same sag duration in some the POW such as in Figure 6. It drops out at sag duration of 20 milliseconds. It can be seen that the contactor is most susceptible to voltage magnitude when it was supplied by $60^{\circ}$ the POW. The voltage magnitude value is $55 \%$.

Investigation in Figure 4 until to Figure 6, contactor to drop out is not similar, however curvesof the susceptibity showing the pattern is almost the similar. In general susceptibility curves of three contactors are almost horizontal in sag magnitude whereas for sag duration are not vertical. Consequently the susceptibity .curves are not rectangular. These indicate that suscepbility of contactors are affected by point of wave of voltage sag initiation. Contactors drop out for sag duration are equalor greater than 20 milliseconds.

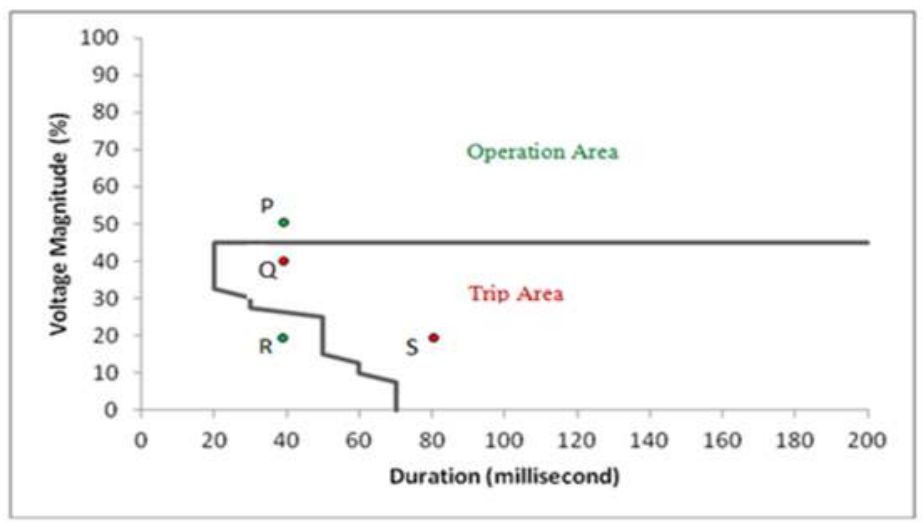


Fig. 3. Susceptibility curve of a contactor

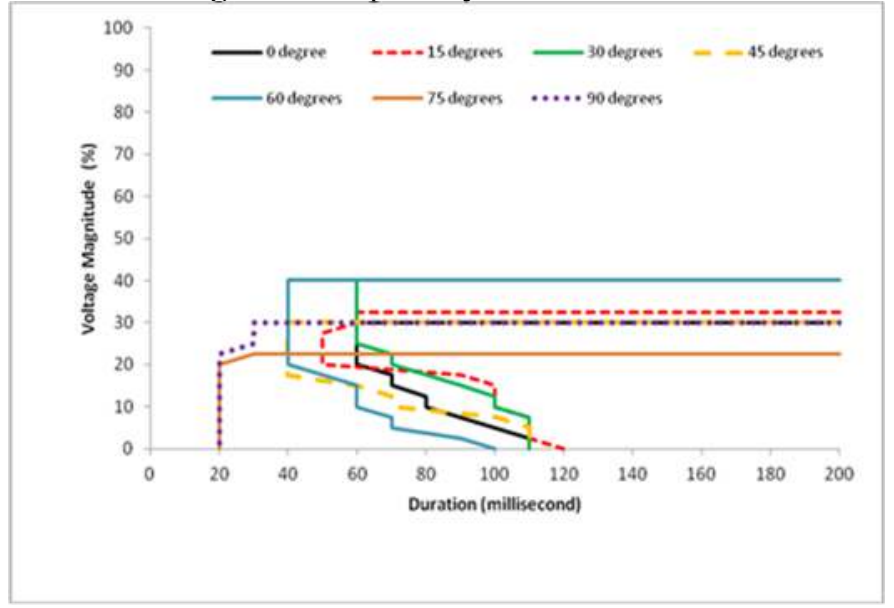

Fig. 4. Susceptibility curves of contactor A in distinct POWs of sag initiation

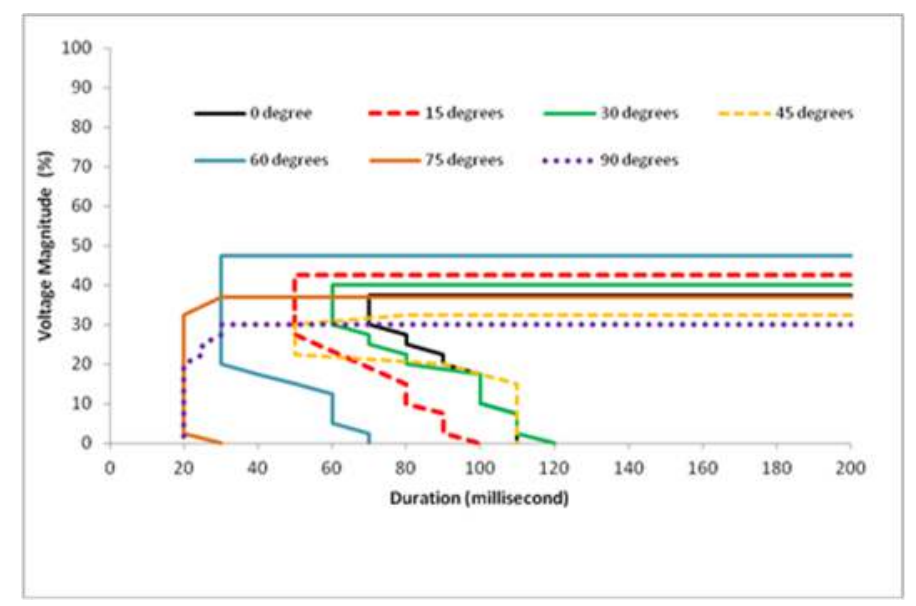

Fig. 5. Susceptibility curves of contactor B in distinct POWs of sag initiation 


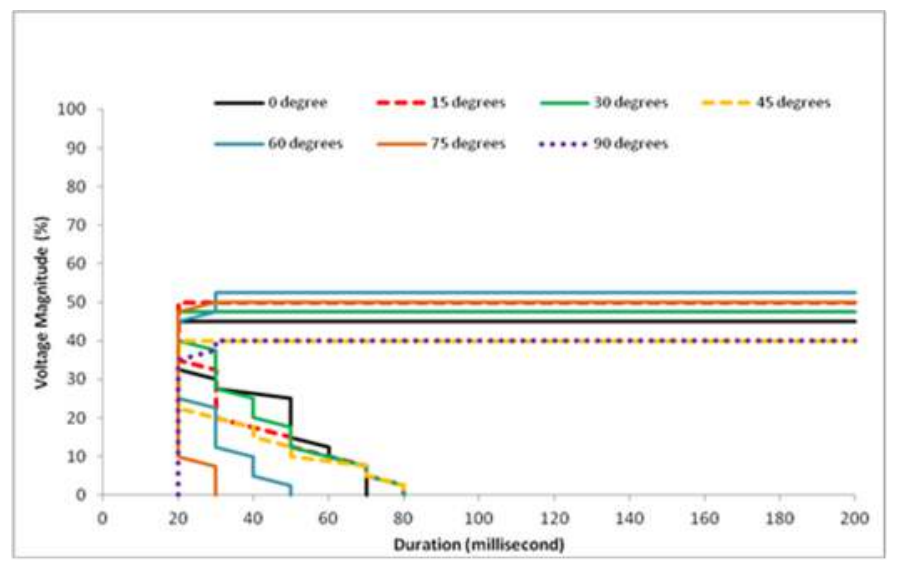

Fig. 6. Susceptibilitycurves of contactor $\mathrm{C}$ in distinct POWs of sag initiation

Figure 7 illustrates susceptibilitiy points in distinct POW. Figure 7 (a) is susceptibitiy points of contactors against sag magnitude. They susceptibility decrease for POW of $0^{\circ}, 45^{\circ}$ and $90^{\circ}$. From this figure can be also explained that three contactors have contactor A. Figure 7 (b) illustrates effect of POW on sag duration. Two contactors (A and B) to be faster to drop out when it was supplied by the POW of $90^{\circ}$. causes contactors to be more susceptible to drop out. Susceptibilty of contactor $\mathrm{C}$ to sag duration some susceptibility curve is almost similar with up and down patern. Sag magnitude with POW of $60^{\circ}$ causes contactors to be more susceptible to drop out. Order ofthe most susceptible arecontactor C, contactor B, the POWs are constant which it drops out at 20 milliseconds and it is not effected by POW. Three contactorshavesimilar susceptibility for POW of $75^{\circ}$ and $90^{\circ}$ and they threshold values are 20 milliseconds.

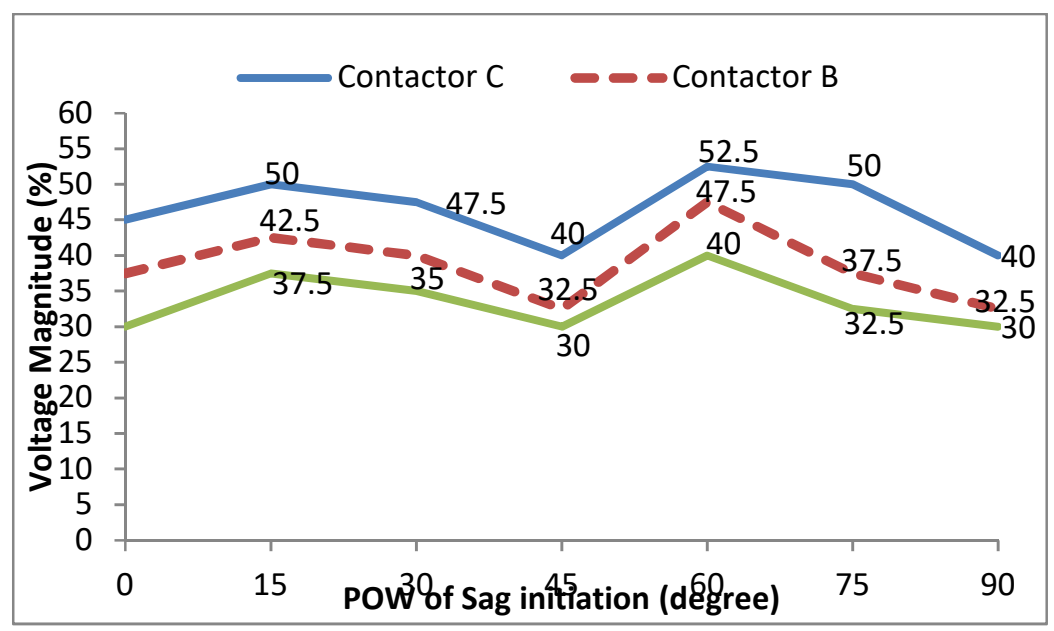

(a) Sag magnitude in distinct the POW 


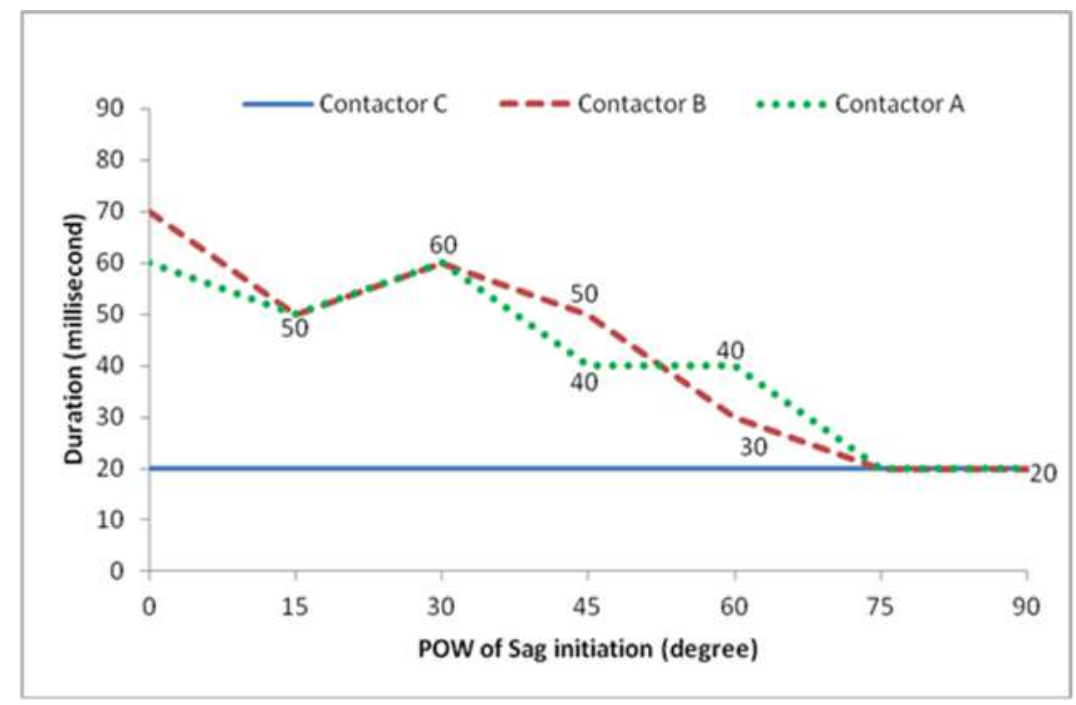

(b) Sag duration in distinct the POW

Fig. 7. .Susceptibitiy points in distinct the POW

\section{Conclusion}

Contactors performance under voltage sags for drop out are not not similar. But the susceptibilty curves show are almost similar patern. The curves in horizontal axes are flat but they are not flat in vertical axes.Even for lower sag, required time for the contactors drop out are longer. These are caused by effect of the POW. Three contactors have same threshold values against sag duration which are 20 milliseconds. The susceptibility curves of the contactors against sag duration decreases when the voltage sags occur with the POW near to $90^{\circ}$. Contactors are most suceptible against sag magnitude for the POWs of $15^{\circ}$ and $60^{\circ}$ whereas for POWs of $0^{\circ}, 45^{\circ}$ and $90^{\circ}$ POW susceptibility decrease.

\section{References}

[1] Bollen, M.H.J. (2000). Understanding Power Quality Problems: Voltage sag and Interruption. IEEE Press.

[2] Dugan, R. C. , Mark F. McGranaghan, Surya S., H. Wayne Beaty, (2003). Electrical Power System Quality. McGraw-Hill.

[3] George, G. K., S. Saksen, B. Shi, N. Senroy (2005). Effects of Voltage Sags on Loads in a Distribution. Final Project Report, Power system engineering research center, Cornell University

[4] Iyoda, I., M. Hirata, N. Shigei, K. Ota and T. ISE (2007). Affect of voltage Sags on Electromagnetic Contactor. 9th International Conference, Electrical Power Quality and Utilization. Barcelona, 9 -11 October.

[5] IEEE Std. 1159 (1995). Recommended Practices for Monitoring Electric Power Quality. IEEE Standards, Piscataway, N. J. November.

[6] Jeong, S.W., G.J. Lee and J.H. Gim, (2009). The Study on the Characteristics of Operating Limits of AC Contactor during Voltage Sag. IEEE T\&D Asia. 
[7] Pohjanheimo, P. and M. Lehtonen, (2002). Equipment Sensitivity to Voltage Sags Test Results for Contactors, PCs and Gas Discharge Lamps.

[8] Harmonics and Power Quality of Power 2002, $10^{\text {th }}$ international Conference IEEE. 